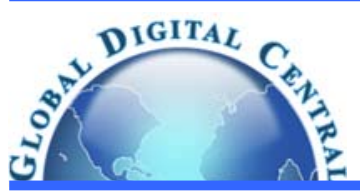

Frontiers in Heat and Mass Transfer

\title{
A NEURAL NETWORK BASED METHOD FOR ESTIMATION OF HEAT GENERATION FROM A TEFLON CYLINDER
}

\author{
Sharath Kumar, Harsha Kumar, N. Gnanasekaran * \\ Department of Mechanical Engineering, National Institute of Technology, Karnataka, Mangalore, India
}

\begin{abstract}
The paper reports the estimation of volumetric heat generation $\left(\mathrm{q}_{\mathrm{v}}\right)$ from a Teflon cylinder. An aluminum heater, which acts as a heat source, is placed at the center of the Teflon cylinder. The problem under consideration is modeled as a three dimensional steady state conjugate heat transfer from the Teflon cylinder. The model is created and simulations are performed using ANSYS FLUENT to obtain temperature data for the known heat generation qv. The numerical model developed using ANSYS acts as a forward model. The inverse model used in this work is Artificial Neural Network (ANN). Estimation of heat generation is carried out by minimizing the error between the simulated temperature and the experimental/surrogated temperature. The efficacy of the ANN method is explored for the estimation of unknown heat generation as both forward model and inverse model. The concept of Asymptotic Computational Fluid Dynamics (ACFD) is introduced as a fast forward model which is obtained by performing CFD simulations. The unknown heat generation is estimated for the surrogated data using ANN. In order to mimic experiments, noise is added to the surrogated data and estimation of heat generation is also carried out for the perturbed/noise added temperature data
\end{abstract}

KEYWORDS: heat generation, CFD, ACFD, Conjugate, ANN, fast forward

\section{INTRODUCTION}

Most of the major engineering applications utilize conduction and convection as their heat transfer phenomenon. Electronic cooling, heat exchangers are examples of its application. The ability to control the thermal process depends on how the designed mathematical model predicts the behavior of the thermal system. Mathematical design requires inputs such as boundary conditions, thermo physical properties and initial conditions. If any of the inputs is unknown, the only way to determine these parameters is by using the concept of parameter estimation. In heat transfer, we estimate the unknown properties using temperature data measured at one or several location at a domain. This type of estimation is called inverse problem. On contrary, if all the aforementioned properties are known then the defined model is well posed and this approach is referred to as direct problem. From past few years a lot of research is being carried out on inverse convection heat transfer due to its wide range of applicability and importance in engineering applications. (Yang, 1998) used the least-squares error method to determine the strength of the temporal dependent heat source when prior knowledge of the source functions is not available in a twodimensional heat conduction problem. A comprehensive detail about inverse heat conduction problems has been given by (Ozisik and Orlande, 2000). (Chen and Yang, 2008) showed that the inverse convection problem is more complex than inverse conduction problem due to its parabolic nature. Energy and momentum equation coupling adds complexity to analysis. Adjoint and conjugate gradient methods were used for inverse convection analysis by (Yang and Chen, 2009; Zhao et al., 2009; Payan et al.2009). (Deng and Hwang, 2006) used non iterative methods are used to solve both forward and inverse conduction problem and showed advantages over iterative methods in terms of computational cost and accuracy. In inverse heat transfer problems deterministic and stochastic methods are used as the inverse methods. Conjugate gradient method and steepest descent method are the forms of deterministic method, whereas Bayesian Inference which forms the stochastic method.

One among the non-iterative method is ANN, also being used for solving inverse convection and inverse conjugate heat transfer problems (Balaji and Kumar, 2010; 2011). ANN can be used as the forward model as well as the Inverse model in heat transfer and other applications. (Torre et al., 2015) used artificial neural network as a modeling tool to predict the strength of high performance concrete based on manufacturing parameters. (Wright et al., 2014) investigated the use of an artificial neural network to perform diagnostic classification of DMCA scans carried out in nuclear medicine to assess the level of functional renal tissue in patients. (Ligor et al., 2015) applied artificial neural network for selection of potential lung cancer biomarkers by obtaining volatile organic compounds (VOCs) in the exhaled breath samples of lung cancer patients. (Hamzaoui et al., 2015) developed an integrated approach using artificial neural network inverse (ANNi) coupling along with a Nelder Mead optimization method to estimate the resonance stress of the turbine blades. (Thibault and Grandjean, 1991) used ANN to correlate heat transfer data. (Zhao and Zhang, 2010) presented neural network approach to the evaluation of performance of the fin and tube air cooled condensers used in air-conditioning and refrigeration systems. (Basheer and Hajmeer, 2000) focused on the use of ANN in solving complex real-world problems. (Kumar et al., 2013) used artificial neural network as a design tool in the area of building services engineering. (Fannou et al., 2014) used ANN to model direct expansion geothermal heat pump. (Krishnan et al., 2003) used asymptotic computational fluid dynamics (ACFD) and obtained correlations for the average Nusselt number, for the mixed convection problem. (Premchandran and Balaji, 2006) developed a correlation for the non-dimensional maximum temperature using the method of asymptotic expansions.

Based on the literature review, most of the research on inverse problems is devoted to the theoretical works and iterative methods are used as inverse method. The problem considered in the present work is conjugate heat transfer from Teflon cylinder which has not 
been discussed by other researchers. Navier stokes equation is solved for the conjugate heat transfer problem and temperature distribution is obtained. In view of this, the main contribution of this study is to develop a numerical model (Forward model) which would reduce the computational cost and to estimate the heat generation in the Teflon cylinder using a non-iterative method. In the ensuing sections, following a brief description about forward model and its validation, detailed evaluation of inverse model and ACFD as a forward model is discussed.

\section{FORWARD MODEL}

The problem deals with a cylindrical aluminum heater inside the Teflon cylinder that provides constant volumetric heat generation $\left(q_{v}\right)$. The heater is placed at the center of the Teflon cylinder. The setup has an aluminum heater with dimensions of $30 \mathrm{~mm}$ diameter and $30 \mathrm{~mm}$ length. The Teflon cylinder with dimensions of $100 \mathrm{~mm}$ diameter and $100 \mathrm{~mm}$ length is considered for the present work. The velocity profiles and the convection effects are thus studied by modeling an extended air domain. The setup is modeled as a three dimensional steady state conjugate heat transfer problem. The geometrical model and the coordinate system considered in the present study are as shown in Fig.1

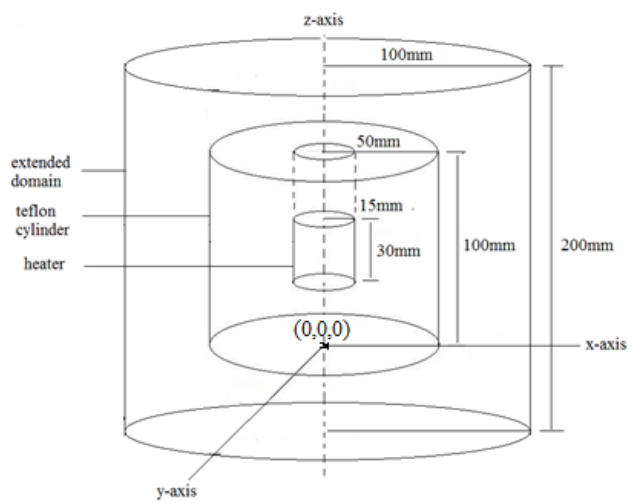

Fig. 1 Schematic representation of the Teflon cylinder along with aluminum heater

The governing equation contains both conduction and convection terms hence one cannot find the exact solution. So the governing equation along with the appropriate boundary conditions is solved using the commercially available CFD package ANSYS fluent 14. The fundamental equations of fluid flow are the continuity equation, momentum equations (Navier Stokes equation) and energy equation. Air is the medium under consideration with constant thermo-physical properties except for density. The assumption of constant density cannot be done in this case since the problem deals with convection and fluid motion in convection is driven by density change and gravity. Hence the density change is modeled using Boussinesq approximation for the buoyancy term in the momentum equation. This approach treats the density as constant in the continuity equation and allows it to change with temperature in gravity term.

The governing equations can be written as

Continuity:

$$
\frac{\partial u}{\partial x}+\frac{\partial v}{\partial y}+\frac{\partial w}{\partial z}=0
$$

$\mathrm{X}$-momentum equation:

$$
\mathrm{u} \frac{\partial u}{\partial x}+\mathrm{v} \frac{\partial u}{\partial y}+\mathrm{w} \frac{\partial u}{\partial z}=-\frac{1}{\rho} \frac{\partial p}{\partial x}+\vartheta\left(\frac{\partial^{2} u}{\partial x^{2}}+\frac{\partial^{2} u}{\partial y^{2}}+\frac{\partial^{2} u}{\partial z^{2}}\right)
$$

Y-momentum equation:

$$
\mathrm{u} \frac{\partial v}{\partial x}+\mathrm{v} \frac{\partial v}{\partial y}+\mathrm{w} \frac{\partial v}{\partial z}=-\frac{1}{\rho} \frac{\partial p}{\partial y}+\vartheta\left(\frac{\partial^{2} v}{\partial x^{2}}+\frac{\partial^{2} v}{\partial y^{2}}+\frac{\partial^{2} v}{\partial z^{2}}\right)
$$

Z-momentum equation:

$$
\mathrm{u} \frac{\partial w}{\partial x}+\mathrm{v} \frac{\partial w}{\partial y}+\mathrm{w} \frac{\partial w}{\partial z}=-\frac{1}{\rho} \frac{\partial p}{\partial x}+\vartheta\left(\frac{\partial^{2} w}{\partial x^{2}}+\frac{\partial^{2} w}{\partial y^{2}}+\frac{\partial^{2} w}{\partial z^{2}}\right)+\mathrm{g} \beta\left(\mathrm{T}-T_{\infty}\right)
$$

Energy equation:

$$
\mathrm{u} \frac{\partial T}{\partial x}+\mathrm{v} \frac{\partial T}{\partial y}+\mathrm{w} \frac{\partial T}{\partial z}=\alpha\left(\frac{\partial^{2} T}{\partial x^{2}}+\frac{\partial^{2} T}{\partial y^{2}}+\frac{\partial^{2} T}{\partial z^{2}}\right)
$$

The governing equation for the conduction inside the Teflon cylinder is given by

$$
k\left(\frac{\partial^{2} T}{\partial x^{2}}+\frac{\partial^{2} T}{\partial y^{2}}+\frac{\partial^{2} T}{\partial z^{2}}\right)+q_{v}=0
$$

The following problem is effectively modeled by applying the boundary conditions as shown in Table 1 .

Table 1 Boundary conditions

\begin{tabular}{|l|l|}
\hline Boundary & Condition \\
\hline Inner cylinder top & Coupled wall \\
\hline Inner cylinder bottom & Coupled wall \\
\hline Inner cylinder lateral & Coupled wall \\
\hline Inner cylinder & Constant heat generation (Aluminum) \\
\hline Outer cylinder top & Coupled wall \\
\hline Outer cylinder bottom & Coupled wall \\
\hline Outer cylinder lateral & Coupled wall \\
\hline Outer cylinder & $\mathrm{k}=0.25 \mathrm{~W} / \mathrm{mK}$ (Teflon) \\
\hline Extended domain top & pressure-outlet \\
\hline Extended domain bottom & pressure-outlet \\
\hline Extended domain lateral & pressure-outlet \\
\hline
\end{tabular}

The meshed portion of the geometry considered is shown in Fig. 2.

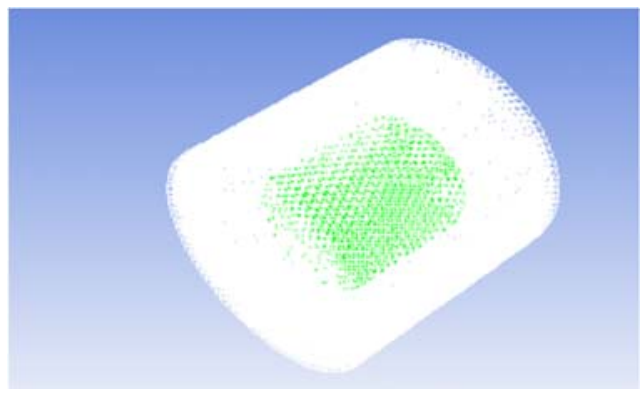

Fig. 2 Schematic of the meshed Teflon cylinder

\subsection{Grid Independence study}

Grid Independence study is performed to fix the optimum grid size for meshing with a balance in computational time and accuracy. The domain is meshed with a coarse mesh and the simulation is performed for fixed convergence criteria until the solution is converged. The grid size is then refined and simulations are studied until solution is not varied. The proper meshing has been selected after carrying out many case studies. Table 2 represents the details 
of grid independence study carried at location $(\mathrm{x}, \mathrm{y}, \mathrm{z})=(50,0,50)$ $\mathrm{mm}$.

Table 2 Grid independence study for $\mathrm{q}_{\mathrm{v}}=5 \times 10^{5} \mathrm{~W} / \mathrm{m}^{3}$

\begin{tabular}{|c|c|c|}
\hline S1 No. & No. of grids & $\mathrm{T}(\mathrm{K})$ \\
\hline 1 & 50000 & 341.95 \\
\hline 2 & 75000 & 342.69 \\
\hline 3 & 90000 & 342.56 \\
\hline 4 & 110000 & 339.83 \\
\hline 5 & 120000 & 339.56 \\
\hline
\end{tabular}

From the grid independence study, the total number of cells considered throughout the entire analysis is fixed to be 110000 . The deviation observed is very less and results can be considered to be reasonably accurate. The forward model is executed with the fixed grid for the heat generation of $300000 \mathrm{~W} / \mathrm{m}^{3}$ and $400000 \mathrm{~W} / \mathrm{m}^{3}$ to obtain temperature distribution of the Teflon cylinder. Fig. 3 shows the temperature distribution on the surface of the Teflon cylinder for the heat flux mentioned previously.

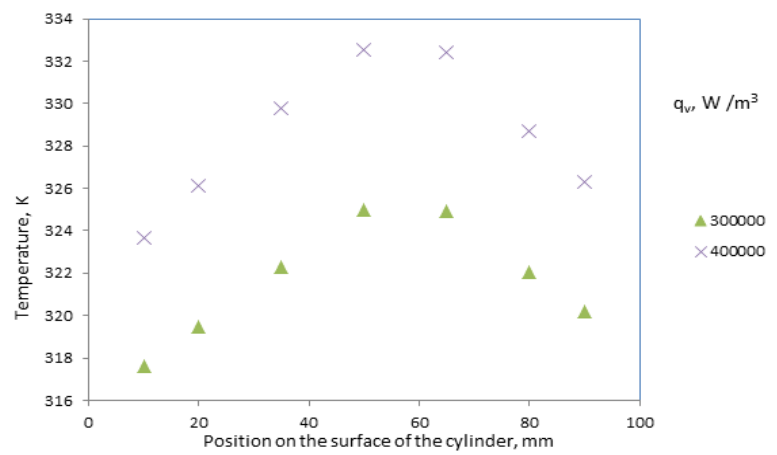

Fig. 3 Temperature distribution along with the surface of the cylinder

CFD Simulations are carried out for different heat generation value as input and the temperature and velocity plot for each of the heat generation value is obtained. One such simulation result is shown in Fig. 4 in which temperature distribution along the surface of the Teflon cylinder is shown and Fig.5 shows the velocity distribution for heat generation value of $\mathrm{q}_{\mathrm{v}}=400000 \mathrm{~W} / \mathrm{m}^{3}$.

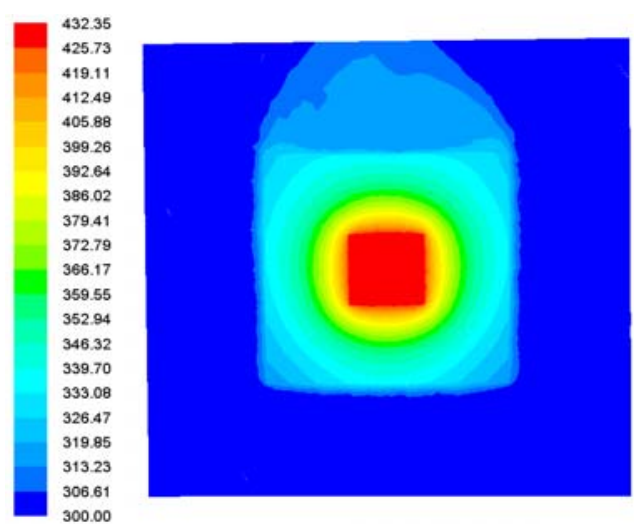

Fig. 4 Temperature $(\mathrm{K})$ distribution in the Teflon cylinder for $\mathrm{q}_{\mathrm{v}}=$ $4 \times 10^{5} \mathrm{~W} / \mathrm{m}^{3}$

\subsection{Forward model - Neural Network}

The temperature data obtained from the forward model (CFD) with heat generation $\mathrm{q}_{\mathrm{v}}$ as input is used to train the artificial neural network. By doing so, the computational cost involved in executing
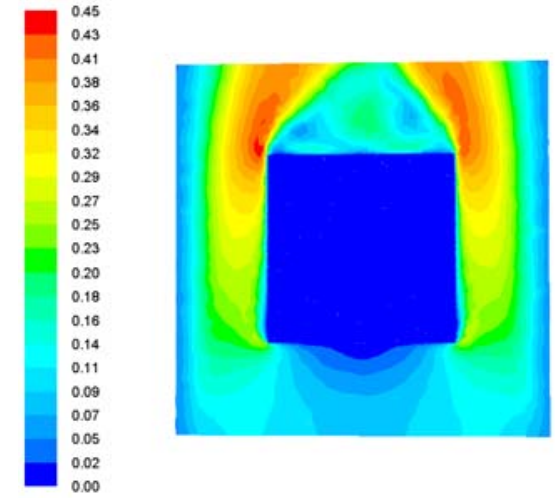

Fig. 5 Velocity $(\mathrm{m} / \mathrm{s})$ contour plot for $\mathrm{q}_{\mathrm{v}}=4 \times 10^{5} \mathrm{~W} / \mathrm{m}^{3}$

the forward model simulations is reduced. Commercially available MATLAB neural network tool box is used to train the neural network. A network is created between heat generation $\mathrm{q}_{\mathrm{v}}$ as input and temperature distribution as output.Similar to grid independence study one should perform neuron independence study in order to obtain better correlation and accuracy. A three layer Neural Network is shown in Fig. 6 and for the present case network input is heat generation $\mathrm{q}_{\mathrm{v}}$ and the network output is temperature. Each layer consists of more neurons that are represented by circular nodes. The first layer input which is called as input layer recieves the information from the user and the output of the particular neuron is passed as the input to the next layer.

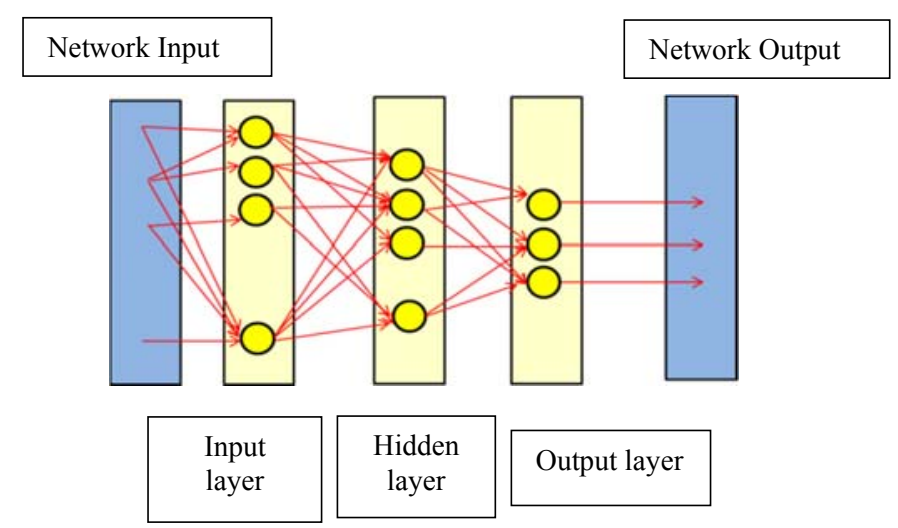

Fig. 6 Schematic of three layer Neural Network

\subsection{Neuron independence study}

The neuron independence study is carried out to fix the optimum number of neurons in the hidden layer. Once the input is specified, the next step is to create a network. The study is started with one neuron and the network is trained with the help of specified input and output data. In order to fix the number of neurons in the hidden layer, a neuron independency study is carried out by increasing the number of neurons from 5 to 15 in the interval of 5 till the satisfactory results are obtained. The feed forward model is trained by Levenberg-Marquardt algorithm. The selection of the network is based on the error on the network training, validation and testing the data. The performance of the network can be expressed in terms of mean relative errors (MRE), mean square errors (MSE) and the coefficient of determination $\mathrm{R}^{2}$. The number of neuron is selected in such a way that the mean square error is less and the regression value approaches one.

Table 3 represents the data tabulated for the trained neural network. The regression coefficient for three different neuron studies is shown in Fig. 7-9. We can observe that 10 neurons are sufficient to train the neural network. 
Table 3 Neuron Independence Study

\begin{tabular}{|c|l|c|l|l|}
\hline Sl. No & $\begin{array}{l}\text { No. of } \\
\text { neurons in } \\
\text { the hidden } \\
\text { layer }\end{array}$ & MRE (\%) & $\mathrm{R}^{2}$ & $\mathrm{R}_{\text {test }}$ \\
\hline 1 & 5 & 0.010137 & 0.99974 & 0.932661 \\
\hline 2 & 10 & 0.0000175 & 0.99999 & 0.997319 \\
\hline 3 & 15 & 0.0019204 & 0.99988 & 0.877846 \\
\hline
\end{tabular}

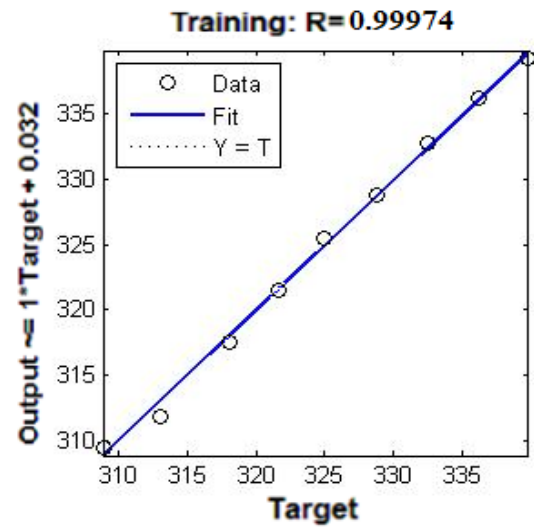

Fig. 7 Regression for 5 neurons in the hidden layer

Training: $\mathbf{R}=\mathbf{0 . 9 9 9 9 9}$

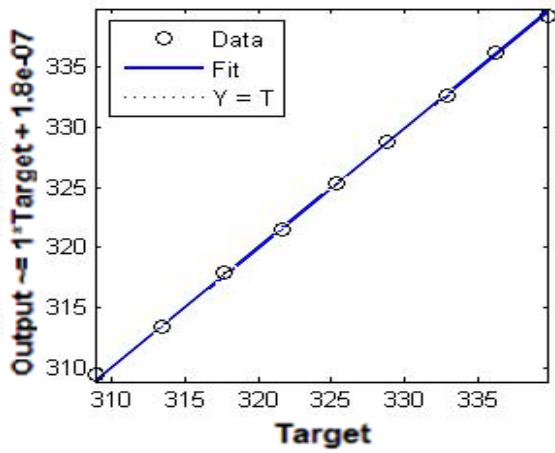

Fig. 8 Regression for 10 neurons in the hidden layer

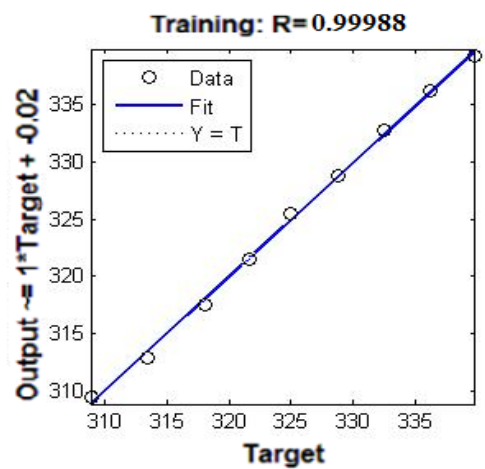

Fig. 9 Regression for 15 neurons in the hidden layer

The numerical model created using CFD is used to obtain temperature distribution on the surface of the Teflon cylinder. The full numerical simulation provides information about temperature for various heat generation $\mathrm{q}_{\mathrm{v}}$. The network is trained between heat generation $\mathrm{q}_{\mathrm{v}}$ and surface temperatures as mentioned earlier. The temperature obtained from full numerical simulation and ANN is compared for different values of $\mathrm{q}_{\mathrm{v}}$ at a particular location say (50, $0,50) \mathrm{mm}$ on the Teflon cylinder. Such a comparison is shown in Table 4. A maximum error of $0.39 \%$ further corroborates that the numerical model can be replaced with ANN model which now becomes a fast forward model to provide temperature information on the surface of the Teflon cylinder.

Table 4 Comparison between full numerical solution and ANN

\begin{tabular}{|l|l|l|l|l|}
\hline & & $\begin{array}{l}\text { Temperature, } \\
\text { K (full } \\
\text { numerical } \\
\text { solution) }\end{array}$ & $\begin{array}{l}\text { Temperature, } \\
\text { K (ANN) }\end{array}$ & $\begin{array}{l}\text { Error } \\
(\%)\end{array}$ \\
\hline 1 & 100000 & 308.85 & 307.89 & 0.31 \\
\hline 2 & 200000 & 317.14 & 316.28 & 0.27 \\
\hline 3 & 300000 & 324.99 & 323.72 & 0.39 \\
\hline 4 & 400000 & 332.54 & 331.44 & 0.33 \\
\hline
\end{tabular}

\subsection{Forward solution using ACFD}

Thus far, the numerical model based on ANN has been used as the forward model. In this section, the concept of Asymptotic Computation Fluid Dynamics (ACFD) is introduced as a forward model. The key point for the problem under consideration is the concept of Asymptotic Computation Fluid Dynamics (ACFD) which acts as a further fast forward model to obtain the temperature distribution. An Asymptotic analysis is the study of behavior of algorithms when the size of the data being processed grows very large. Asymptotic Computational Fluid Dynamics (ACFD) is the combination of asymptotic analysis with Computational Fluid Dynamics (CFD).The ACFD forward model provides the information about temperature for the given input $\mathrm{q}_{\mathrm{v}}$. The asymptotic expansion approach is the expansion of the solution to the problem from the particular solution taken as reference solution.

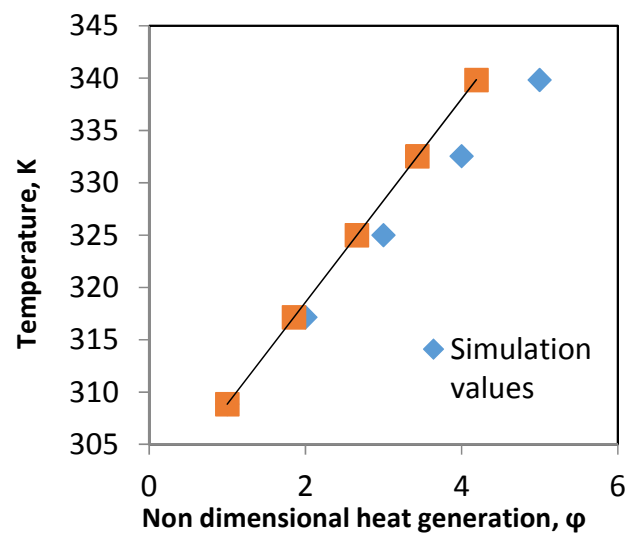

Fig. 10 Variation of temperature with variable qv

The ACFD correlation for the model is given as

$$
\begin{aligned}
& \quad T=T_{o}+\frac{\Delta T}{\Delta \varnothing}\left(\varnothing-\varnothing_{0}\right) \\
& T=308.85+9.72\left[\left(q_{v} / q_{v, r e f}\right)^{0.89}-1\right] \\
& \text { where } \varnothing=\left(q_{v} / q_{v, \text { ref }}\right)^{0.89}
\end{aligned}
$$

$\frac{\Delta T}{\Delta \emptyset}=$ slope obtained from the linearized plot

$T_{o}=$ Reference temperature value, $\mathrm{K}$

$q_{v}=$ Given heat generation value, $\left(\mathrm{W} / \mathrm{m}^{3}\right)$

$q_{v, r e f}=$ Reference heat generation value, $100000\left(\mathrm{~W} / \mathrm{m}^{3}\right)$

Fig. 10 shows the linearized temperature values obtained from simulated temperatures. CFD simulations are carried out for various input values of heat generation and the temperature plotted with respect to the heat generation ratio $\left(q_{v} / q_{v, r e f}\right)$, now this plot is linearized by subjecting it to a power law relation which is termed 
as linearized plot in Fig.10. Based on the plot obtained Eq. (7) is obtained which forms the ACFD correlation.

Eq. (7) is the temperature correlation obtained using ACFD with respect to heat generation $\mathrm{q}_{\mathrm{v}}$. Eq. (8) gives the value of temperature for any given value of heat generation. The ACFD correlation thus obtained reduces the computational time and hence used as the forward model in the present work. Table 5 shows a comparison between CFD and ACFD temperature values at $(50,0$, 50) $\mathrm{mm}$.

Table 5 Comparison between temperatures obtained from CFD and ACFD

\begin{tabular}{|l|l|l|l|l|}
\hline $\begin{array}{l}\text { S. } \\
\text { No }\end{array}$ & $\begin{array}{l}\text { Volumetric } \\
\text { heat } \\
\text { generation( } \\
\left.\mathrm{W} / \mathrm{q}^{3}\right)\end{array}$ & $\begin{array}{l}\text { Simulation } \\
\text { temperature, } \\
\text { K (CFD) }\end{array}$ & $\begin{array}{l}\text { Forward } \\
\text { model } \\
\text { temperature, } \\
\text { K (ACFD) }\end{array}$ & Error (\%) \\
\hline 1 & 150000 & 311.91 & 313.07 & 0.37 \\
\hline 2 & 250000 & 320.26 & 321.09 & 0.26 \\
\hline 3 & 350000 & 327.38 & 328.76 & 0.42 \\
\hline 4 & 450000 & 335.04 & 336.19 & 0.34 \\
\hline
\end{tabular}

From Table 5, it is observed that a maximum error of $0.42 \%$ is obtained, which indicates that the correlation obtained from ACFD as a forward model predicts the temperature very close to the simulated temperature. Therefore, it has been safely concluded that the ACFD model as a forward model that can accurately predict the temperature in estimating the unknown heat generation inside the Teflon cylinder.

\section{RESULTS AND DISCUSSION}

\subsection{Inverse problem - Neural network}

In the inverse problem, estimation of heat generation is done for the known temperture distribution from the Teflon cylinder. The inverse method adopted is also Artificial Neural Network. The temperature data obtained through CFD analysis is given as input and heat flux is obtained as output. It should be noted that the Neural Network inverse model also requires neuron independence study and such an exercise is reported in the next section.

\subsection{Neuron independence study- ANN as the forward model}

A neuron independence study was carried out to determine the optimum number of neurons in the hidden layer.

Table 6 Neuron independence study for the inverse model

\begin{tabular}{|l|l|l|l|l|}
\hline Sl. No & $\begin{array}{l}\text { No. of } \\
\text { neurons in the } \\
\text { hidden layer }\end{array}$ & MSE (\%) & Rtraining & R test \\
\hline $\mathbf{1}$ & $\mathbf{5}$ & 0.0335651 & 0.99995 & 0.99923 \\
\hline 2 & 8 & 0.00101929 & 0.99999 & 0.99972 \\
\hline 3 & 10 & 0.160204 & 0.99980 & 0.99839 \\
\hline
\end{tabular}

Table 6 represents the data tabulated for inverse model neural network. From Table 6 we can observe that 8 neurons are sufficient to train the neural network.

\subsection{Neuron independence study- ACFD as the forward model}

A neuron independence study was carried out to determine the optimum number of neurons in the hidden layer for ACFD model.

Table 7 represents the data tabulated for inverse model neural network. From the table we can observe that 8 neurons are sufficient to train the neural network in order to obtain the target data.
Table 7 Neuron independence study for inverse model

\begin{tabular}{|c|c|c|c|l|}
\hline $\begin{array}{l}\text { Sl. } \\
\text { No }\end{array}$ & $\begin{array}{l}\text { No. of } \\
\text { neurons in the } \\
\text { hidden layer }\end{array}$ & MSE (\%) & $\mathrm{R}_{\text {training }}$ & $\mathrm{R}_{\text {test }}$ \\
\hline 1 & 5 & 0.025874 & 0.9994 & 0.99949 \\
\hline 2 & 8 & 0.0010027 & 1.0000 & 0.99983 \\
\hline 3 & 10 & 0.24869 & 0.9973 & 0.99745 \\
\hline
\end{tabular}

\subsection{Retrieval of heat generation $\mathrm{q}_{\mathrm{v}}, \mathrm{W} / \mathrm{m}^{3}$}

Single parameter estimation is attempted in this section for the known temperature distribution. It must be noted that to estimate the unknown heat generation $\mathrm{q}_{\mathrm{v}}, \mathrm{W} / \mathrm{m}^{3}$ experimental/surrogated temperature is required. In other words, the surrogated temperature is obtained by the procedure given in Fig. 11.

(INPUT)

(OUTPUT)

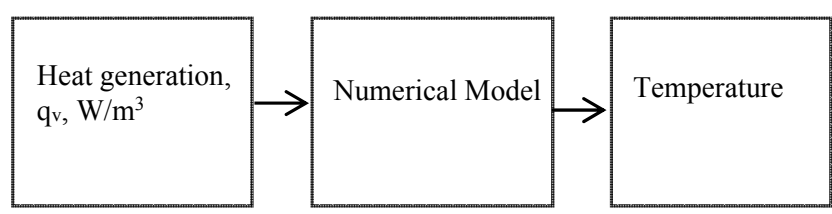

Fig. 11 Schematic representation of surrogated temperature

The surrogated temperature obtained from CFD simulation and ACFD is fed into the neural network which also acts as an inverse model to obtain $\mathrm{q}_{\mathrm{v}}$. Table 8 shows the retrieved $\mathrm{q}_{\mathrm{v}}$ from the surrogated temperature data obtained at $(50,0,50) \mathrm{mm}$ on the surface of the Teflon cylinder. For example, from Table 9 when a temperature of $317.14 \mathrm{~K}$ is specified as input to the inverse model, the estimated heat generation turns out to be $196912 \mathrm{~W} / \mathrm{m}^{3}$. This in turn, compared with the heat generation reported in Table 9 for the same temperature. More precisely, the error between the actual and estimated heat generation is $1.5 \%$ for ANN model and $2.08 \%$ for ACFD model which is within the acceptable limit.

Table 8 Retrieval of heat generation

\begin{tabular}{|l|l|l|l|}
\hline S. No & $\begin{array}{l}\text { Temperature } \\
(\mathrm{K}) \text { at } \\
(50,0,50) \mathrm{mm}\end{array}$ & $\begin{array}{l}\mathrm{q}_{\mathrm{v}} \text { retrieved from } \\
\text { ANN }\left(\mathrm{W} / \mathrm{m}^{3}\right)\end{array}$ & $\begin{array}{l}\mathrm{q}_{\mathrm{v}} \text { retrieved } \\
\text { from ACFD } \\
\left(\mathrm{W} / \mathrm{m}^{3}\right)\end{array}$ \\
\hline 1 & 317.14 & 196912 & 195840 \\
\hline 2 & 324.99 & 295569 & 294987 \\
\hline 3 & 332.54 & 396582 & 396038 \\
\hline
\end{tabular}

The retrieved value of internal heat generation $\mathrm{q}_{\mathrm{v}}, \mathrm{W} / \mathrm{m}^{3}$ is now given as input to the forward model to obtain the simulated temperature distribution. The simulated and experimental temperature are compared and shown in a parity plot Fig 12. Surprisingly, the simulated temperatures using forward model and the surrogated temperatures agree very well.

\subsection{Retrieval of heat generation for perturbed temperature data}

In the early investigations, estimation of heat generation $\mathrm{q}_{\mathrm{v}}$ was attempted for the surrogated data. In actual practice, experimental temperature contains inherent noise and this has motivated the authors to carry out an estimation process for the noise added or perturbed temperature data. Hence, in this study $0.5 \%$ and $1 \%$ noise is added to the surrogated data and estimation of heat generation is 


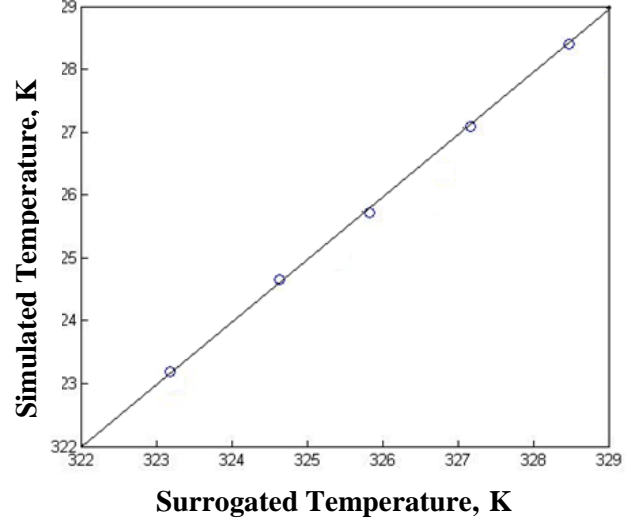

Fig. 12 Parity plot showing agreement of simulated temperature with surrogated temperature.

is carried out. Table 8 shows the retrieved value of heat generation and the simulated temperature obtained by the inverse method for the noise added data. As seen in Table 9, the proposed method is capable of estimating the unknown heat generation using ANN with a maximum error of $4 \%$ and $7 \%$ between the retrieved value for $0.5 \%$ and $1 \%$ noise and actual value of heat generation $\mathrm{q}_{\mathrm{v}}$. The parity plot shown in Fig.13 further corroborates the agreement of the simulated and surrogated temperature.

Table 9 Retrieved heat generation $\mathrm{q}_{\mathrm{v}}, \mathrm{W} / \mathrm{m}^{3}$ for noise added surrogated temperature

\begin{tabular}{|c|c|c|c|}
\hline S. No & $\begin{array}{l}\text { Actual } \mathrm{q}_{\mathrm{v}} \\
\left(\mathrm{W} / \mathrm{m}^{3}\right)\end{array}$ & $\begin{array}{l}\mathrm{q}_{\mathrm{v}} \text { retrieved by } \\
\text { adding } 0.5 \% \text { noise } \\
\left(\mathrm{W} / \mathrm{m}^{3}\right)\end{array}$ & $\begin{array}{l}\text { qv retrieved by } \\
\text { adding } 1 \% \text { noise } \\
\left(\mathrm{W} / \mathrm{m}^{3}\right)\end{array}$ \\
\hline 1 & 200000 & 191595 & 187520 \\
\hline 2 & 300000 & 318475 & 279330 \\
\hline 3 & 400000 & 383891 & 423840 \\
\hline
\end{tabular}

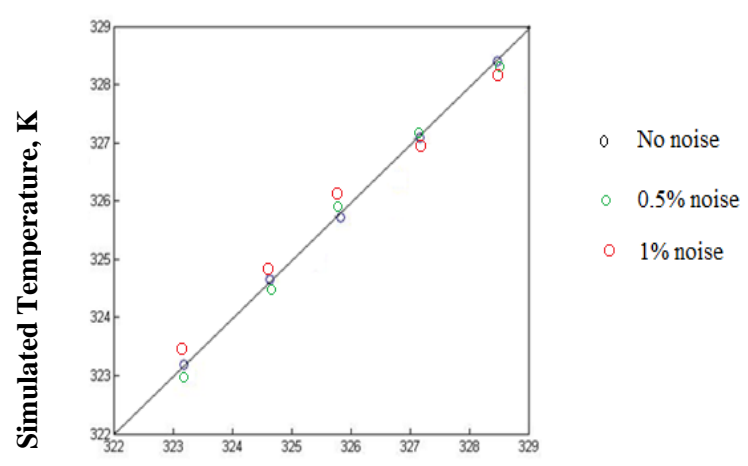

Surrogated Temperature, $\mathrm{K}$

Fig. 13 Parity plot showing agreement of simulated temperature with the noise added surrogated temperature

\section{CONCLUSIONS}

In a novel approach, the unknown volumetric heat generation $\left(\mathrm{q}_{\mathrm{v}}\right)$ has been estimated for the surrogated temperature of the Teflon cylinder using artificial neural network as an inverse model. The forward model for the three dimensional conjugate heat transfer has been solved using the commercially available software ANSYS 14. A simple ACFD model has been proposed. ANN and ACFD are used to replace the forward model to save computational cost. ANN method was also used as an inverse model to estimate qv from the surrogated temperatures obtained from CFD simulations. A maximum error of $0.39 \%$ was observed between temperature obtained from CFD and ANN and a maximum error of $0.37 \%$ between temperature obtained from CFD and ACFD. The unknown heat generation retrieved for the surrogated as well as noise added temperature data was under the reasonable limit. Finally, it has been concluded that the well trained ANN method is a powerful technique for the estimating the volumetric heat generation from surface temperature data.

\section{NOMENCLATURE}

$\begin{array}{ll}\text { ANN } & \text { artificial neural networks } \\ \text { ACFD } & \text { asymptotic computational fluid dynamics } \\ \text { CFD } & \text { computational fluid dynamics } \\ \mathrm{g} & \text { acceleration due to gravity }\left(\mathrm{m} / \mathrm{s}^{2}\right) \\ \mathrm{h} & \text { heat transfer coefficient }(\mathrm{W} / \mathrm{m} 2 \mathrm{~K}) \\ \mathrm{k} & \text { thermal conductivity }(\mathrm{W} / \mathrm{mK}) \\ \text { MRE } & \text { mean relative error } \\ \mathrm{q}_{\mathrm{v}} & \text { volumetric heat generation }\left(\mathrm{W} / \mathrm{m}^{3}\right) \\ \mathrm{q}_{\mathrm{v}, \text { ref }} & \text { reference volumetric heat generation }\left(\mathrm{W} / \mathrm{m}^{3}\right) \\ \mathrm{R}^{2} & \text { correlation coefficient } \\ \mathrm{T} & \text { temperature }(\mathrm{K}) \\ \text { T } & \text { ambient temperature }(\mathrm{K}) \\ \text { Greek Symbols } & \\ \alpha & \text { thermal diffusivity }\left(\mathrm{m}^{2} / \mathrm{s}\right) \\ \beta & \text { Boussinesq approximation } \\ v & \text { kinematic viscosity }\left(\mathrm{m}^{2} / \mathrm{s}\right) \\ \rho & \text { density }\left(\mathrm{kg} / \mathrm{m}^{3}\right) \\ \varphi & \left(q_{v} / q_{v, r e f}\right)^{0.89}\end{array}$

\section{REFRENCES}

Kumar A. and Balaji C., 2010, "A Principal Component Analysis And Neural Network Based Non-Iterative Method For Inverse Conjugate Natural Convection," International Journal of Heat and Mass Transfer, 53, 4684-4695. http://dx.doi.org/10.1016/j.ijheatmasstransfer.2010.06.025

Kumar A. and Balaji C., 2011, "ANN Based Estimation of Heat Generation From Multiple Protruding Heat Sources on a Vertical Plate Under Conjugate Mixed Convection," International Journal of Thermal Sciences, 50, 532-543.

http://dx.doi.org/10.1016/j.ijthermalsci.2010.11.003

Basheer I. A and Hajmeer M., 2000, "Artificial Neural Networks: Fundamentals, Computing, Design and Application," Journal of Microbiological Methods, 43 (1), 3-31. http://dx.doi.org/10.1016/S0167-7012(00)00201-3

Deng S. and Hwang Y., 2006, "Applying Neural Networks to the Solution of Forward and Inverse Heat Conduction Problems," International Journal of Heat and Mass Transfer, 49, 4732-4750. http://dx.doi.org/10.1016/i.ijheatmasstransfer.2006.06.009

Hamzaoui El., Rodríguez J.A., Hernández J.A., Victor S., 2015,"Optimization of Operating Conditions for Steam Turbine 
Using an Artificial Neural Network Inverse," Applied Thermal Engineering, 75, 648-657.

http://dx.doi.org/10.1016/j.applthermaleng.2014.09.065

Jean-Louis C.F., Clément R., Louis L, Stanislaw K.,2014, "Modeling of a Direct Expansion Geothermal Heat Pump Using Artificial Neural Networks," Energy and Buildings, 81, 381-390. http://dx.doi.org/10.1016/j.enbuild.2014.06.040

Krishnan A.S., Balaji C., Venkateshan, S. P., 2003, "A Synergistic Approach to Parameter Estimation in Multimode Heat Transfer," International Communications in Heat Mass Transfer, 40, 515-524. http://dx.doi.org/10.1016/S0735-1933(03)00080-0

Kumar R., Aggarwal R. K., Sharma J.D., 2013, "Energy Analysis of a Building Using Artificial Neural Network: a Review," Energy and Buildings, 65, 352-358.

http://dx.doi.org/10.1016/j.enbuild.2013.06.007

Ozisik M.N. and Orlande H.R.B.,2000, Inverse Heat Transfer: Fundamental and Applications. Taylor and Francis, New York.

Payan S., Sarvari S.M.H., Ajam H., 2009, "Inverse Boundary Design of Square Enclosures with Natural Convection," International Journal of Thermal Sciences, 48, 682-690. http://dx.doi.org/10.1016/j.ijthermalsci.2008.05.019

Premachandran B., Balaji C., 2006, "Conjugate Mixed Convection With Surface Radiation from a Horizontal Channel With Protruding Heat Sources," International Journal of Heat and Mass Transfer, 49, 3568-3582.

http://dx.doi.org/10.1016/j.ijheatmasstransfer.2006.02.044
Thibault J., Grandjean B.P.A., 1991, "Neural Network Methodology for Heat Transfer Data Analysis," International Journal of Heat and Mass Transfer, 34 (8), 2063-2070.

http://dx.doi.org/10.1016/0017-9310(91)90217-3

Tomasz L., Łukasz P., Bogusław B., 2015, “Application of an Artificial Neural Network Model for Selection of Potential Lung Cancer Biomarkers," Journal of Breath Research, 9 (2), 020301026005.

http://dx.doi.org/10.1088/1752-7155/9/2/027106

Torre A., Garcia F., Moromi I., Espinoza P., Acuña L., 2015, "Prediction of Compression Strength of High Performance Concrete Using Artificial Neural Networks," Journal of Physics: Conference Series, Vol. 582.

http://iopscience.iop.org/1742-6596/582/1/012010

Wen-Lih C., Yu-Ching Y., 2008, "On the Inverse Heat Convection Problem of the Flow Over a Cascade of Rectangular Blades," International Journal of Heat and Mass Transfer, 51, 4184-4194. http://dx.doi.org/10.1016/j.ijheatmasstransfer.2008.02.002

Wright J. W., Duguid R., Mckiddie F., Staff R.T., 2014, "Automatic Classification of DMSA Scans Using an Artificial Neural Network," Physics in Medicine and Biology, 59 (7) 1533-1872. http://dx.doi.org/10.1088/0031-9155/59/7/1789

Yang C.Y., 1998, "Solving the Two Dimensional Inverse Heat Source Problem Through the Linear Least-Squares Error Method," International Journal of Heat and Mass Transfer, 41, 393-398. http://dx.doi.org/10.1016/S0017-9310(97)00125-7 